\title{
Undernutrition and associated factors among 24-36-month-old children in slum areas of Bahir Dar city, Ethiopia
}

This article was published in the following Dove Press journal:

International Journal of General Medicine

9 March 2017

Number of times this article has been viewed

\author{
Yeshalem Mulugeta \\ Demilew' \\ Dagninet Derebe Abie ${ }^{2}$ \\ 'Department of Nutrition, School \\ of Public Health, College of \\ Medicine and Health Sciences, Bahir \\ Dar University, ${ }^{2}$ Department of \\ Pharmacology, College of Medicine \\ and Health Sciences, Bahir Dar \\ University, Bahir Dar, Ethiopia
}

Background: This study aimed to assess undernutrition and associated factors among 24-36-month-old children in the slum areas of Bahir Dar city.

Methods: A community-based cross-sectional study was conducted among 480 children from May 1 to 26, 2015. The simple random sampling technique was used to select respondents. Data were collected using a structured interviewer-administered questionnaire. Statistical Package for Social Sciences version 20 was used for analysis. The prevalence of undernutrition was computed. Binary and multivariable logistic regression analyses were also carried out to identify the association between the independent and dependent variables and the predictors of undernutrition, respectively. A $P$-value $<0.05$ was considered to be statistically significant in the final model.

Result: The prevalence of stunting, underweight, and wasting was $42 \%, 22.1 \%$, and $6.4 \%$, respectively. Independent predictors for stunting were illness in the preceding two weeks, having two children under three years old, taking prelacteal feeding, and early or late initiation of complementary feeding. Illness in the preceding two weeks, lack of latrine utilization, and lack of hand washing practice were independent predictors for underweight.

Conclusion: There was a high prevalence of undernutrition in this study. Thus, health extension workers and health professionals in Bahir Dar city should educate mothers/caretakers on the health impact of giving prelacteal feeding, hand washing practice, time of initiation of complementary feeding, and birth interval.

Keywords: children, stunting, underweight, wasting

\section{Introduction}

Malnutrition continues to be a significant public health and development concern. Across the world, in 2015, the numbers of stunted, overweight, and wasted children under five years old were about 159 million, 41 million, and 50 million, respectively. ${ }^{1}$ This burden is not evenly distributed: three-fourths of the world's malnourished children were found in Sub-Saharan Africa and South Asia. ${ }^{2}$

Malnutrition, with its serious consequences, is rampant in Ethiopia; according to the 2014 Mini-Ethiopian Demographic and Health Survey (Mini-EDHS) report, $40 \%, 25 \%$, and $9 \%$ of under-five-year-olds were stunted, underweight, and wasted, respectively. ${ }^{3}$ Furthermore, within the country, the magnitude of malnutrition varies from region to region. There was also interregional variation of malnutrition and its predictors owing to the type of diet, customs, beliefs, and child-rearing practices. The highest prevalence of malnutrition was reported to be in the Amhara region (the region where the study was conducted), where the prevalence of stunting, at $42 \%$, is higher than it is at the national level $(40 \%){ }^{3}$
Correspondence: Yeshalem Mulugeta Demilew

School of Public Health, College of Medicine and Health Sciences, Bahir Dar University, Bahir Dar, Ethiopia

Tel +251918783819

Email yeshalem_mulugeta@yahoo.com 
Moreover, urban slum dwellers are less educated; marginalized; exposed to poor housing, overcrowding, poor quality of drinking water, and inadequate sanitation; of low socioeconomic status; and less likely to have access to basic health care facilities. ${ }^{4}$ Children living under such conditions are always at a high risk of developing malnutrition and other health problems. ${ }^{5,6}$ So slum areas need special attention to prevent undernutrition.

Child undernutrition is the leading contributor to childhood morbidity and mortality. Globally, it was estimated that undernutrition is responsible for $35 \%$ of under-five mortality. ${ }^{7}$ In addition, undernutrition before age three has an adverse causal effect on physical and mental growth and development, contributing to poor educational performance, besides reducing adult size and capacity for physical work with an impact on economic productivity at the national level. ${ }^{8}$ Furthermore, it increased the risk of nutrition-related chronic disease later in life. ${ }^{9}$

The cause of malnutrition is complex and multifactorial. Inadequate food intake, living standards, water and sanitation, birth weight, birth interval, parity, sex of the child, weaning practices, and mother's education are a few of the important factors that have been identified from research studies carried out on the subject. ${ }^{10}$

Owing to high nutritional requirements for growth and development, infants and young children are more affected by undernutrition than other segments of the population. The Federal Government of Ethiopia has been working to reduce undernutrition significantly through public education and by providing nutritional supplements and financial support to vulnerable families. However, the risk factors involved in undernutrition are multiple and could potentially vary in space and time. In the absence of any study on the subject pertaining to the slum areas of Ethiopia, there was a need to determine the current nutritional status to review the pitfalls and design effective intervention strategies. This study was designed to assess the prevalence of undernutrition and associated factors among young children living in the slum areas of Bahir Dar city.

\section{Methods}

\section{Study setting}

The study was conducted in the slum areas of Bahir Dar city, which is the capital city of Amhara Regional State, located $565 \mathrm{~km}$ from Addis Ababa, Northwest Ethiopia. For administrative purposes, the town is divided into nine subcities, three of which (Shumabo, Gish-Abay, and Sefene-selam) are slums. The majority of the residents in the slum areas are daily laborers and petty traders. The total population of the town is 288,200 , of which 146,982 were females. According to the Bahir Dar City administration health bureau report, the numbers of under-five-year-old children and children aged 24-36 months were 4,227 and 895, respectively. ${ }^{11}$

The town has four hospitals (one public regional referral hospital, one public primary hospital, and two private general hospitals), 6 health centers, 2 nongovernmental clinics, 9 private special higher clinics, 2 private higher clinics, and 12 private clinics to deliver a range of health care services such as health promotion and preventive, curative, and rehabilitative services to the community. ${ }^{11}$

\section{Study design and study population}

A community-based cross-sectional study was conducted from May 1 to 26, 2015. All 24-36-month-old children in the slum areas of Bahir Dar city were the study population.

\section{Sample size, sampling procedure, and data collection}

The sample size was determined using the single population proportion formula on the basis of the following assumptions: $95 \%$ confidence level, proportion of stunting 52\% (as noted in the EDHS 2011 report), ${ }^{12}$ marginal error of $4.75 \%$, and $15 \%$ nonresponse rate. The final sample size was 480 .

The sample frame was the list of 24-36-month-old children in the slum areas registered by the urban health extension workers. Using this registration logbook, the study participants were selected by the simple random sampling technique (lottery method) in proportion to the size of each slum area. In those households that had two children aged 24-36 months, one child was selected by the lottery method.

\section{Data collection tools and techniques}

Sociodemographic data were collected by a structured interviewer-administered questionnaire adapted from previous studies. ${ }^{12}$ The questionnaire was developed in English and translated into Amharic, back-translated to English by an independent translator for consistency. The questionnaire was pretested in a similar setting (not included in the main study). Interviews with mothers were conducted at their homes to ensure privacy. The anthropometric data were collected following the procedure stipulated by the World Health Organization $^{13}$ for the purpose. The equipment used to measure the anthropometric variables was calibrated each day prior to the actual data collection using a material of known weight. Four diploma nurses and two public health professionals were recruited as data collectors and supervisors, respectively. 
Height was measured by a vertical or horizontal measuring board and required each child to stand on the measuring board barefooted, hands hanging loosely with feet parallel to the body, and heels, buttocks, shoulders, and back of the head touching the board. The head would be held comfortably erect. The headpiece of the measuring board was then pushed gently, making contact with the top of the head. Height was read to the nearest $0.1 \mathrm{~cm}$. Two readings were recorded, and the computed average was used in the analysis. Weight was measured using an easily portable weighing scale. The scale was adjusted by setting it to zero before weighing every child. The child was lightly dressed while having the weight taken. Weight was read to the nearest $0.1 \mathrm{~kg}$. Two readings were taken for each child, and the average was recorded on the questionnaire.

The levels of stunting (height for age $z$-scores), underweight (weight for age $z$-scores), and wasting (weight for height $z$-score) were calculated using the Emergency Nutrition Assessment (ENA) for SMART 2011 software (SMART Tech, Calgary, AB, USA). Thus, children who were below -2 standard deviations of the WHO 2006 reference for height for age, weight for age, and weight for height were defined as stunted, underweight, and wasted, respectively, whereas children who were below -3 standard deviations for each of the above indicators were considered severely stunted, severely underweight, and severely wasted. A child was considered undernourished if he or she was stunted or underweight or wasting.

The dependent variables are stunting, underweight, and wasting, whereas the independent variables are sociodemographic characteristics of their parents (marital status of the mother and educational and occupational status of the parents), hand washing practice of the mother, and latrine utilization of the family.

\section{Data quality control}

To ensure the quality of data, two days' intensive training was given for the data collectors and the supervisors on the technique of data collection, instrument use, and how to maintain ethical standards. Pre-testing was done in a similar setting outside the study area on $5 \%$ of the sample size. The weight measuring scale and height measuring stadiometer were checked after each measurement. The supervisor and investigators closely supervised the data collection technique on a daily basis, reviewed the completed questionnaires for completeness, and returned incomplete questionnaires to data collectors for correction. Feedback was given daily.

\section{Data processing and analysis}

Data were entered and analyzed using Statistical Package for the Social Sciences (SPSS) version 20 (IBM Corporation, Armonk, NY, USA). Descriptive summaries such as frequencies, proportions, percentages, mean, standard deviations, and prevalence were determined. The ENA for SMART 2011 software was used to determine the prevalence of malnutrition. Binary and multivariable logistic regression analyses were also carried out to identify the association between the independent and the dependent variables and the predictors of undernutrition, respectively. $P$-value $\leq 0.2$ was taken as a cut-off point to select eligible variables for the multiple logistic regression models. A $P$-value of less than 0.05 was considered statistically significant in the final model.

\section{Ethical considerations}

The study was approved by the Institutional Review Board of Bahir Dar University. Letters of permission were obtained from the respective administrations. Verbal consent was taken from mothers or caregivers. Privacy and confidentiality were maintained throughout the study period by excluding personal identifiers from the data collection forms. Children who had malnutrition were referred to nearby health institutions for treatment.

\section{Results \\ Sociodemographic characteristics of children and their parents}

Of the 480 children sampled, 471 participated in this study, giving a response rate of $98.1 \%$. Two hundred and forty eight $(52.7 \%)$ children were males. The mean age of the children was $30( \pm 4.3 \mathrm{SD})$ months. One-third of their mothers, and $154(32.7 \%)$ and 101 (21.4\%) of their fathers had no formal education. Nearly half, 225 (47.8\%), of their mothers were housewives, and $218(46.3 \%)$ of their fathers were daily laborers. Four hundred (84.9\%) children lived with both their biological parents. Two hundred and six (58.6\%) parents made joint decisions on the use of money in the household (Table 1).

\section{Nutritional status of children}

Prevalence figures for stunting, underweight, and wasting among study participants were $42 \%$ (95\% CI: $37.8,46.5)$, $22.1 \%$ (95\% CI: $18.1,26.1)$, and 6.4\% (95\% CI: 4.2, 8.7), respectively. Prevalence of severe stunting, underweight, and wasting among the children was $16.3 \%$ (95\% CI: 13.2, 19.7), $3.8 \%$ (95\% CI: $2.1,5.7)$, and $1.3 \%$ (95\% CI: $0.4,2.3$ ), respectively (Table 2). 
Table I Sociodemographic characteristics of children and their parents in the slum areas of Bahir Dar city; Ethiopia, May 2015

\begin{tabular}{|c|c|c|}
\hline Variables & $\begin{array}{l}\text { Frequency } \\
(\mathrm{n}=47 \mathrm{I})\end{array}$ & Percentage \\
\hline \multicolumn{3}{|l|}{ Sex of the child } \\
\hline Male & 248 & 52.7 \\
\hline Female & 223 & 47.3 \\
\hline \multicolumn{3}{|l|}{ Religion } \\
\hline Orthodox & 398 & 84.5 \\
\hline Protestant & 21 & 4.5 \\
\hline Muslim & 52 & II \\
\hline \multicolumn{3}{|l|}{ Ethnicity } \\
\hline Amhara & 427 & 90.7 \\
\hline Others $^{\mathrm{a}}$ & 44 & 9.3 \\
\hline \multicolumn{3}{|c|}{ Educational status of the mother } \\
\hline Have no formal education & 154 & 32.7 \\
\hline Primary education & 129 & 27.4 \\
\hline Secondary education & 130 & 27.6 \\
\hline College and above & 58 & 12.3 \\
\hline \multicolumn{3}{|c|}{ Occupational status of the mother } \\
\hline Housewife & $225+$ & 47.8 \\
\hline Daily laborer & 147 & 31.2 \\
\hline Government employee & 58 & 12.3 \\
\hline Petty trader & 26 & 5.5 \\
\hline Private employee & 15 & 3.2 \\
\hline \multicolumn{3}{|l|}{ Marital status of the mother } \\
\hline Married & 404 & 85.8 \\
\hline Never married & 48 & 10.2 \\
\hline Widowed & 12 & 2.5 \\
\hline Divorced & 7 & 1.5 \\
\hline \multicolumn{3}{|c|}{ Child's mother works outside the house } \\
\hline Yes & 246 & 52.2 \\
\hline No & 225 & 47.8 \\
\hline \multicolumn{3}{|c|}{ Hours the mother spent outside home to } \\
\hline work (hours) & 72 & 15.3 \\
\hline$<8$ & 104 & 22.1 \\
\hline 8 & 70 & 14.9 \\
\hline$>8$ & 225 & 47.8 \\
\hline \multicolumn{3}{|l|}{ Not applicable } \\
\hline \multicolumn{3}{|l|}{ The child currently lives with } \\
\hline Both parents & 400 & 84.9 \\
\hline His mother only & 7I & 15.1 \\
\hline \multirow{2}{*}{\multicolumn{3}{|c|}{$\begin{array}{l}\text { Number of children }<3 \text { years old in the } \\
\text { household }\end{array}$}} \\
\hline & & \\
\hline One & 416 & 88.3 \\
\hline Two & 55 & 11.7 \\
\hline \multicolumn{3}{|c|}{ Decision maker on use of money } \\
\hline Both parents & 276 & 58.6 \\
\hline The father & 112 & 23.8 \\
\hline The mother & 83 & 17.6 \\
\hline \multicolumn{3}{|l|}{ Educational status of the father } \\
\hline Has no formal education & 101 & 21.4 \\
\hline Primary education & 110 & 23.4 \\
\hline Secondary education & 184 & 39.1 \\
\hline College and above & 76 & 16.1 \\
\hline \multicolumn{3}{|c|}{ Occupational status of the father } \\
\hline Daily laborer & 218 & 46.3 \\
\hline Government employee & 101 & 21.4 \\
\hline Merchant & 64 & 13.6 \\
\hline Driver & 45 & 9.6 \\
\hline Private employee & 43 & 9.1 \\
\hline
\end{tabular}

Table I (Continued)

\begin{tabular}{lll}
\hline Variables & $\begin{array}{l}\text { Frequency } \\
(\mathbf{n = 4 7})\end{array}$ & Percentage \\
\hline Family size & & \\
$\leq 4$ & 305 & 64.8 \\
$>4$ & 166 & 35.2 \\
\hline
\end{tabular}

Note: ${ }^{A}$ Agew, Tigry, and Oromo.

Table 2 Nutritional status of children in slum areas of Bahir Dar city, Ethiopia, May 2015 ( $n=47 \mathrm{I})$

\begin{tabular}{|c|c|c|c|c|}
\hline Variables & Male & Female & Total & $\begin{array}{l}\text { Confidence } \\
\text { level }\end{array}$ \\
\hline \multicolumn{5}{|l|}{ Stunted } \\
\hline Yes & $109(44.0)$ & $89(40.0)$ & $198(42.0)$ & $(37.8,46.5)$ \\
\hline No & $139(56.0)$ & $134(60.0)$ & $273(58.0)$ & $(53.5,62.2)$ \\
\hline \multicolumn{5}{|c|}{ Severely stunted } \\
\hline Yes & $51(20.6)$ & $26(11.7)$ & $77(16.3)$ & $(13.2,19.7)$ \\
\hline No & $197(79.4)$ & $197(88.3)$ & 394 (83.7) & $(80.3,86.8)$ \\
\hline \multicolumn{5}{|c|}{ Underweight } \\
\hline Yes & $61(24.6)$ & $43(19.3)$ & $104(22.1)$ & $(18.1,26.1)$ \\
\hline No & $187(75.4)$ & $180(80.7)$ & 367 (77.9) & $(73.8,81.9)$ \\
\hline \multicolumn{5}{|c|}{ Severely underweight } \\
\hline Yes & $13(5.2)$ & $5(2.2)$ & $18(3.8)$ & $(2.1,5.7)$ \\
\hline No & $235(94.8)$ & $218(97.8)$ & $453(96.2)$ & $(94.3,97.9)$ \\
\hline \multicolumn{5}{|l|}{ Wasted } \\
\hline Yes & $17(6.9)$ & I3 (5.8) & $30(6.4)$ & $(4.2,8.7)$ \\
\hline No & $231(93.1)$ & $210(94.2)$ & $44 I(93.6)$ & $(91.3,95.8)$ \\
\hline \multicolumn{5}{|c|}{ Severely wasted } \\
\hline Yes & $5(2.0)$ & $\mathrm{I}(0.4)$ & $6(1.3)$ & $(0.4,2.3)$ \\
\hline No & $243(98.0)$ & $222(99.6)$ & $465(98.7)$ & $(97.7,99.6)$ \\
\hline
\end{tabular}

\section{Factors associated with stunting}

Binary logistic regression analysis showed that the marital status of the mother, the occupational status of the mother and father, the educational status of the mother and father, possession of television and radio, time of initiation of complementary feeding, taking prelacteal feed, being a male or female decision maker on use of money in the household, illness in the preceding two weeks, and having more than one under-three-year-old child were statistically associated with stunting (Table 3).

In multivariable logistic regression analysis, children who had illness in the preceding two weeks were 2.6 times as likely to develop stunting as children who were not ill (adjusted odds ratio $[\mathrm{AOR}]=2.6,95 \% \mathrm{CI}$ : $[1.4,4.9])$; children who resided in a household that had more than one under-three-year-old child were 1.8 times as prone to developing stunting as their counterparts $(\mathrm{AOR}=1.8,95 \% \mathrm{CI}$ : $[1.0,3.4])$; children who took prelacteal feed were 2.3 times as likely to be stunted as their counterparts (AOR $=2.3,95 \% \mathrm{CI}$ : $[1.1,4.6]$ ); children who started complementary food before six months of age were 2.1 times $(\mathrm{AOR}=2.1,95 \% \mathrm{CI}:[1.2,3.4])$ and those who started after six months of age were 1.8 times $(\mathrm{AOR}=1.8$, 
Table 3 Factors associated with stunting in slum areas of Bahir Dar city; Ethiopia, May 2015

\begin{tabular}{|c|c|c|c|c|}
\hline \multirow[t]{2}{*}{ Factors } & \multicolumn{2}{|l|}{ Stunted } & \multirow[t]{2}{*}{ COR $(95 \% \mathrm{Cl})$} & \multirow[t]{2}{*}{ AOR $(95 \% \mathrm{Cl})$} \\
\hline & $\overline{\text { Yes }}$ & No & & \\
\hline \multicolumn{5}{|l|}{ Marital status of the mother } \\
\hline Married & $161(34.2)$ & $243(51.6)$ & 1.00 & \\
\hline Widowed/divorced/never married & $37(7.8)$ & $30(6.4)$ & $\mathrm{I} .8(\mathrm{I} . \mathrm{I}, 3.1)$ & \\
\hline \multicolumn{5}{|l|}{ Occupational status of the mother } \\
\hline Housewife & $93(19.8)$ & $132(20.0)$ & $1.6(0.9,2.6)$ & \\
\hline Daily laborer & $75(15.9)$ & $72(15.3)$ & $2.3(1.4,4.0)$ & \\
\hline G/P. employee and petty trader & $30(6.4)$ & $69(14.6)$ & 1.00 & \\
\hline \multicolumn{5}{|l|}{ Educational status of the mother } \\
\hline Has no formal education & $75(15.9)$ & $79(16.8)$ & $1.9(1.2,3.0)$ & \\
\hline Primary education & $62(13.1)$ & $67(14.2)$ & $1.9(1.2,3.0)$ & \\
\hline Secondary and above education & $61(13.0)$ & I $27(27.0)$ & 1.00 & \\
\hline \multicolumn{5}{|l|}{ Possession of television } \\
\hline Yes & $108(22.9)$ & $189(40.1)$ & $\mathrm{I} .8(1.2,2.7)$ & \\
\hline No & $90(19.1)$ & $84(17.9)$ & 1.00 & \\
\hline \multicolumn{5}{|l|}{ Possession of radio } \\
\hline Yes & $67(14.2)$ & $126(26.8)$ & $1.6(1.1,2.4)$ & \\
\hline No & 131 (27.8) & $147(3 \mid .2)$ & 1.00 & \\
\hline \multicolumn{5}{|l|}{ The child lives with } \\
\hline Both parents & $161(34.2)$ & $239(50.7)$ & 1.00 & \\
\hline The mother only & $37(7.9)$ & $34(7.2)$ & $1.6(0.9,2.6)$ & \\
\hline \multicolumn{5}{|l|}{ Illness in the past 2 weeks } \\
\hline Yes & $36(7.6)$ & $20(4.2)$ & $2.8(1.5,5.0)$ & $2.6(1.4,4.9)$ \\
\hline No & $162(34.4)$ & $253(53.7)$ & 1.00 & 1.00 \\
\hline \multicolumn{5}{|c|}{ Number of children $<3$ years old in the household } \\
\hline One & $165(35.0)$ & $251(53.3)$ & 1.00 & 1.00 \\
\hline Two & $33(7.0)$ & $22(4.7)$ & $2.2(1.2,4.0)$ & $1.8(1.0,3.4)$ \\
\hline \multicolumn{5}{|l|}{ Decision maker on use of money } \\
\hline Both parents jointly & $89(19.0)$ & $187(39.7)$ & 1.00 & 1.00 \\
\hline The father only & $65(13.8)$ & $47(10.0)$ & $2.9(1.8,4.5)$ & $2.1(1.2,3.4)$ \\
\hline The mother only & $44(9.3)$ & $39(8.2)$ & $2.3(1.4,3.9)$ & $\mathrm{I} .8(\mathrm{I} .0,3.2)$ \\
\hline \multicolumn{5}{|l|}{ Educational status of the father } \\
\hline Has no formal education & $54(11.5)$ & $47(10.0)$ & $3.0(1.5,5.6)$ & \\
\hline Primary education & $47(10.0)$ & $63(13.3)$ & $1.9(1.0,3.6)$ & \\
\hline Secondary education & $76(16.1)$ & $108(22.9)$ & $1.8(1.0,3.2)$ & \\
\hline More than secondary education & $21(4.5)$ & $55(11.7)$ & 1.00 & \\
\hline \multicolumn{5}{|l|}{ Give prelacteal feeding } \\
\hline Yes & 32 & 17 & $2.9(1.5,5.3)$ & $2.3(I . I, 4.6)$ \\
\hline No & 166 & 256 & 1.00 & 1.00 \\
\hline \multicolumn{5}{|l|}{ Initiation of complementary food } \\
\hline Before 6 months & $55(11.7)$ & $45(9.6)$ & $2.22(1.4,3.5)$ & $2.1(1.2,3.4)$ \\
\hline After 6 months & $31(6.6)$ & $24(5.0)$ & $2.35(1.3,4.2)$ & I.8 (I.0, 3.5) \\
\hline At 6 months & $112(23.8)$ & $204(43.3)$ & 1.00 & 1.00 \\
\hline
\end{tabular}

Abbreviations: COR, crude odds ratio; AOR, adjusted odds ratio; $\mathrm{Cl}$, confidence interval; G/P, government/private employee.

95\% CI: $[1.0,3.5])$ as likely to be stunted as children who started complementary food at six months; children who lived in households where their fathers decided on use of money were 2.1 times (AOR $=2.1,95 \% \mathrm{CI}$ : $[1.2,3.4]$ ) and children who lived in households where their mothers decided on use of money were 1.8 times ( $\mathrm{AOR}=1.8,95 \% \mathrm{CI}$ : $[1.0,3.2]$ ) as likely to be stunted as children who lived in households where both parents made decisions jointly (Table 3 ).

\section{Factors associated with underweight}

Binary logistic regression analysis showed that the following factors were statistically associated with underweight (Table 4): religion, educational status of the mother, possession of television, lack of latrine utilization, caregivers/mothers who did not wash their hands after latrine use, being a male decision maker on use of money, having illness in the preceding two weeks, and having more than one under-three child. 
Table 4 Factors associated with underweight in slum areas of Bahir Dar city; Ethiopia, May 2015

\begin{tabular}{|c|c|c|c|c|}
\hline \multirow[t]{2}{*}{ Factors } & \multicolumn{2}{|c|}{ Underweight } & \multirow{2}{*}{$\begin{array}{l}\text { COR } \\
(95 \% \mathrm{CI})\end{array}$} & \multirow{2}{*}{$\begin{array}{l}\text { AOR } \\
(95 \% \mathrm{CI})\end{array}$} \\
\hline & $\overline{\text { Yes }}$ & No & & \\
\hline \multicolumn{5}{|l|}{ Religion } \\
\hline Orthodox & $8 I(I 7.2)$ & $317(67.3)$ & 1.00 & \\
\hline Muslim and & $23(4.9)$ & $50(10.6)$ & $1.8(1.0,3.1)$ & \\
\hline \multicolumn{5}{|l|}{ Protestant } \\
\hline \multicolumn{5}{|l|}{$\begin{array}{l}\text { Possession of } \\
\text { television }\end{array}$} \\
\hline Yes & $48(10.2)$ & $126(26.8)$ & $1.6(1.0,2.5)$ & \\
\hline No & 56 (11.9) & $24 \mid(5 \mid .2)$ & 1.00 & \\
\hline \multicolumn{5}{|l|}{ Illness in the past } \\
\hline \multicolumn{5}{|l|}{2 weeks } \\
\hline Yes & $24(5.1)$ & $32(6.8)$ & $3.1(1.7,5.6)$ & $3.1(1.6,6.2)$ \\
\hline No & $80(17.0)$ & $335(7 I .1)$ & 1.00 & 1.00 \\
\hline \multicolumn{5}{|l|}{$\begin{array}{l}\text { Decision maker on } \\
\text { use of money }\end{array}$} \\
\hline Both parents & $46(9.8)$ & $230(48.8)$ & & \\
\hline The father only & $36(7.7)$ & $76(16.1)$ & $2.3(1.4,3.9)$ & \\
\hline The mother only & $22(4.6)$ & $61(13)$ & $1.8(1.0,3.2)$ & \\
\hline \multicolumn{5}{|l|}{$\begin{array}{l}\text { Educational status of } \\
\text { the father }\end{array}$} \\
\hline $\begin{array}{l}\text { Have no formal } \\
\text { education }\end{array}$ & $36(7.7)$ & $65(13.8)$ & & \\
\hline Primary education & $26(5.5)$ & $84(17.8)$ & $3.6(1.6,7.9)$ & \\
\hline $\begin{array}{l}\text { Secondary } \\
\text { education }\end{array}$ & $32(6.8)$ & $152(32.2)$ & $2.0(0.9,4.5)$ & \\
\hline $\begin{array}{l}\text { More than } \\
\text { secondary education }\end{array}$ & $10(2.1)$ & $66(14.0)$ & I.3 $(0.6,2.9)$ & \\
\hline \multicolumn{5}{|l|}{ The family use latrine } \\
\hline Yes & 97 & 327 & & 1.00 \\
\hline No & 7 & 40 & $1.6(0.7,3.9)$ & $3.3(1.2,8.7)$ \\
\hline \multicolumn{5}{|l|}{$\begin{array}{l}\text { The mother washes } \\
\text { her hands after use } \\
\text { of toilet }\end{array}$} \\
\hline Yes & $18(3.8)$ & $223(47.3)$ & 1.00 & 1.00 \\
\hline No & $86(18.3)$ & $144(30.6)$ & $7.3(4.2,12.8)$ & $\begin{array}{l}6.7 \\
(3.8,11.8)\end{array}$ \\
\hline
\end{tabular}

Abbreviations: $\mathrm{COR}$, crude odds ratio; $\mathrm{AOR}$, adjusted odds ratio; $\mathrm{Cl}$, confidence interval.

In the multivariable logistic regression analysis, children who had illness in the preceding two weeks were 3.1 times as likely to develop underweight as children who were not ill (AOR =3.1, 95\% CI: $[1.6,6.2])$; children who resided in households in which latrines were not used were 3.3 times as prone to developing underweight as their counterparts (AOR $=3.3,95 \% \mathrm{CI}:[1.2,8.7])$; and children whose mothers/caregivers did not wash their hands after latrine use were 6.7 times as likely to develop underweight as their counterparts $(\mathrm{AOR}=6.7,95 \% \mathrm{CI}$ : $[3.8,11.6])$ (Table 4).

\section{Discussion}

The main aim of this study was to assess undernutrition and associated factors among 24-36 month-old-children in the slum areas of Bahir Dar city. Stunting in children was linked with delay in motor and mental development as well as with low physical strength and economic productivity in adulthood. ${ }^{14}$ In spite of its serious consequences, the prevalence of stunting was found to be high in this study $(42 \%$, [95\% CI: $37.8,46.5])$. This is comparable with the findings of previous studies in Botswana (38.7\%), ${ }^{15}$ Cameroon (41.2\%), ${ }^{16}$ Mumbai urban slums (42.8), ${ }^{17}$ and the urban slums of Vadodara city $(46.1 \%){ }^{18}$

However, this rate of prevalence is higher than that in previous studies in the slum areas of Kolkata $(25 \%){ }^{19}$ West Bengal, India (28\%); ${ }^{20}$ and the urban slums of Dhaka, Bangladesh (36\%). ${ }^{21}$ The discrepancy might be due to differences in the study setting and subjects; in this study, the majority of mothers and fathers were less educated and worked as petty traders/daily laborers. The findings are lower than those of studies in the slums of Dibrugarh town India $(53.1 \%)^{22}$, Nepal $(55.7 \%)^{23}$ and the informal urban settlements of Nairobi, Kenya (47\%). ${ }^{24}$ The difference might be due to the time gap between studies; currently, nutrition education is disseminated through the mass media and by professionals.

The prevalence of underweight was $22.1 \%$ (95\% CI: 18.1 , 26.1). This is similar to the findings of a study in the urban slums of Dhaka, Bangladesh (24\%). ${ }^{21}$ On the other hand, this prevalence is higher than that found by a study on Botswana $(15.6 \%) .{ }^{15}$ This study finding is lower than those pertaining to semiurban areas in Kottayam, Kerala, ${ }^{25}$ and urban slums of Pune ${ }^{26}$ and Sri Lanka (27.2\%). ${ }^{27}$ The prevalence of wasting was $6.4 \%(95 \% \mathrm{CI}: 4.2,8.7)$. This is similar to what was found by studies conducted in Botswana $(5.5 \%)^{15}$ and the urban slums of Dhaka, Bangladesh $(8 \%) \cdot{ }^{21}$ However, this finding is higher than that which emerged from studies in informal urban settlements in Nairobi, Kenya $(2.6 \%)^{22}$ and Cameroon $(3.8 \%) .{ }^{16}$ The high prevalence of acute malnutrition might be due to low levels of parental education as well as differences in sample size and study design between studies. This prevalence is lower than that found by previous studies in Nepal $(18.6 \%)^{23}$ and Sri Lanka (21.5\%). ${ }^{27}$ The lower prevalence of acute malnutrition compared with the case in previous studies might be a result of current nutritional programs.

Children living in households with more than one underthree-year-old child were 1.8 times as likely to develop stunting as their counterparts living in households with one under-three-year-old child. This is consistent with previous studies in Ludhiana and Botswana. ${ }^{15,28}$

This might be due to the negative effect of the increased number of children on growth stemming from the heavy burden on the mother's reproductive and nutritional resources, as well as from greater competition for the scarce resources within the household. 
The prevalence of stunting was higher among children who started complementary foods after age six months, followed by children who received complementary foods before six months of age compared with their counterparts who started complementary foods at six months of age. This finding is consistent with that of previous studies in Meskan district, South Ethiopia, and in the urban slums of Ludhiana and Mumbia. ${ }^{17,27-29}$ Inappropriate timing of introducing complementary foods may affect the child's nutritional status negatively. Owing to the immaturity of his or her digestive and immune systems, early introduction of complementary foods, especially under unhygienic conditions, predisposed to illness. In addition, it might be due to the negative impact of early introduction of complementary foods on breastfeeding frequency and duration. If complementary food is not introduced at six months of age along with breast milk, the heightened nutritional needs of the infant go unsatisfied.

Infection plays a major role in the etiology of undernutrition because of increased requirements and high energy expenditure, lower appetite, nutrient losses, utilization of nutrients, and disruption of metabolic equilibrium. Illness within 15 days before the study was associated with undernutrition. Similar findings are reported from previous study findings. ${ }^{20,30,31}$ Infection predisposed to malnutrition through increased metabolic reaction and nutrients lost through vomiting, diarrhea, and malabsorption.

More children who lived in households in which males made decisions on the use of money were stunted than their counterparts who lived in households in which both parents made decisions jointly. This finding is supported by previous study findings. ${ }^{32,33}$ In households in which males made decisions on use of money, women lacked one component of maternal autonomy, making them unable to provide effective child nutrition and eventually impacting child growth. Children residing in households where females made decisions were also prone to undernutrition. This was because of the socioeconomic status of the mothers. In this study, female decision makers were single, daily laborers and lived in rented houses with earthen floors with no ceiling. So even if they had the freedom to purchase, they had financial constraints in doing so.

The odds of being underweight were higher in children residing in households where family members did not use latrines as compared with children living in households where their family members used latrines. This finding is consistent with the findings of previous studies. ${ }^{34-36}$ This is because family members who did not use latrines practiced open field defecation, which predisposed them to various diseases.
Children who received prelacteal feed were more likely to develop stunting than those who did not take prelacteal feed. A similar finding is reported from previous studies conducted in many developing countries. ${ }^{37-39}$ Prelacteal feeding increases the risk of gastrointestinal infection, deprives the child of colostrum, and discourages exclusive breast-feeding practice and the benefits associated with it. The study may have limitations in regard to recall bias and absence of data on maternal nutrition, heights of the mothers, household food security, and parasitic infections.

\section{Conclusion and recommendation}

The prevalence of undernutrition was high in this study. Factors associated with stunting included illness in the last two weeks, having more than one under-three child, taking prelacteal feed, early or late initiation of complementary feeding, and living in households where males made decisions on the use of money. Illness in the preceding two weeks, lack of latrine utilization, and lack of hand washing practice of mothers/caregivers were positively associated with underweight. Thus, health extension workers and health professionals in Bahir Dar city will be deployed to educate mothers/caretakers on the health impact of giving prelacteal feeding and birth interval, benefit of hand washing practice, and time of initiation of complementary feeding.

\section{Author contributions}

YMD and DDA conceived and designed the study, conducted statistical analysis and result interpretation, prepared the manuscript. The authors read and approved the manuscript.

\section{Acknowledgments}

We would like to thank Bahir Dar University for financial support. The authors are indebted to the study participants who participated in this study and provided valuable information with their full cooperation. We are also grateful to the data collectors and supervisors for their time and full commitment.

\section{Disclosure}

The authors report no conflicts of interests in this work.

\section{Reference}

1. UNICEF, WHO, and World Bank. Levels and Trends in child Malnutrition, UNICEF - WHO - World Bank Group Joint Child Malnutrition Estimates, Key Findings of the 2015 Edition. New York, NY: UNICEF; 2015.

2. UNCF. Improving Child Nutrition: The Achievable Imperative for Global Progress New York, USA. New York, NY: UNICEF; 2013.

3. Central Statistical Agency, and Ministry of Health. Ethiopia Mini Demographic and Health Survey 2014. Addis Ababa, Ethiopia: Central Statistical Agency; 2014. 
4. Un-Habitat. Defining Slums: Towards an Operational Definition for Measuring Slums,'Background Paper 2, Expert Group Meeting on Slum Indicators. Nairobi, Kenya: United Nations; 2002.

5. Munesh KS, Dinesh K, Poonam CM, Goel N. Status of child undernutrition: some socio-demographic concerns in Allahabad, Uttar Pradesh. Indian J Prev Soc Med. 2011;42(1):39-43.

6. Alon U. Children's health in slum settings. Arch Dis Child. 2013:1-7.

7. Rajiv S, Prabhu S, Bhuvaneshwari T, et al. Burden of childhood diseases and malnutrition in a semi-urban slum in southern India. BMC Public Health. 2013;13:87.

8. Hoddinott J, Maluccio J, Behrman JR, et al. The consequences of early childhood growth failure over the life course. Poster presented at: IFPRI International Food and Policy Research Institute; March 2011; Washington, DC.

9. Portrait F, Teeuwiszen E, Deeg D. Early life undernutrition and chronic diseases at older ages: the effects of the Dutch famine on cardiovascular diseases and diabetes. Elsevier. 2011;73(5):711-718.

10. Babatunde RO, Olagunju FI, Fakayode SB, Sola-Ojo FB. Prevalence and determinants of malnutrition among under-five children of farming households in Kwara State, Nigeria. J Agr Sci. 2011;3(3):173-181.

11. Central Statistics Agency. Population and House Census of Ethiopia, Ethiopia, 2007; CSA, Ethiopia, 2012.

12. Central Statistical Agency [Ethiopia], and ICF International. Ethiopia Demographic and Health Survey 2011. Addis Ababa, Ethiopia: Central Statistical Agency; 2012.

13. World Health Organization. Physical status: the use and intrepretation of anthropopmentry. 1995. Available from http://apps.who.int/iris/bitstream/10665/37003/1/WHO_TRS_854.pdf.Accessed February 21, 2017.

14. Dewey KG, Begum K. Long-term consequences of stunting in early life. Matern Child Nutr. 2011;7(s5):5-18.

15. Salah EOM, Maria N, Theodore B. Factors affecting prevalence of malnutrition among children under three years of age in Botswana. Afr J Food Agr Nutr Dev. 2006;6(1):1-15.

16. Nicolas PN, Marie MKS, Marlyne JM, Tetanye E, Inocent G. Assessment of nutritional status of preschool children in the Bangang rural community, Cameroon. Int J Biotechnol Food Sci. 2014;2(2):44-52.

17. Saiprasad B, Mahajan H, Rajan K. Maternal and environmental factors affecting the nutritional status of children in Mumbai urban slum. Int $J$ Sci Res Publ. 2012;2(11):2250-3153.

18. Popat CN, Chaudhari AI, Mazumdar VS, Patel SV. A cross sectional study to measure the prevalence of malnutrition and factors associated with malnutrition among under five children of an urban slum of Vadodara city. J Res Med Dent Sci. 2014;2(3):59-64.

19. Sudarsan M, Ram PV, Jayita P, Parthasarathi R, Rahul B. An assessment of nutritional status of children aged 0-14 years in a slum area of Kolkata. Int J Med Publ Health. 2014;4(2):159-162.

20. Aparajita D, Sanjaya KS, Pranita T, et al. Composite index of anthropometric failure and its important correlates: a study among under-5 children in a slum of Kolkata, West Bengal, India. Int J Med Sci Publ Health. 2015;4(3):414-419.

21. Sultan-Uz-Zaman, Seoty NR, Haque MAR, Yasmin N. Household food insufficiency and child nutritional status in urban slum, Dhaka, Bangladesh. Acta Med Int. 2015;2(1):65-69.

22. Ajanta D, Alak B. A cross sectional study on nutritional status of preschool children in slums of Dibrugarh Town. J Evol Med Dent Sci. 2013;2(15):2411.
23. Resham BK, Shiva RM, Vishnu K, Bishnu C. Factors associated with underweight among children of former-Kamaiyas in Nepal. Front Public Health. 2015;3:11.

24. Beatrice O, Heather B, Leonard C, et al. Nutritional status of underfive children living in an informal urban settlement in Nairobi, Kenya. J Health Popul Nutr. 2011;29(4):357-363.

25. Binu A, Tony L, Jose J, Ajan MJ, Ajith R. Prevalence of malnutrition among underfive children in a semi urban area in Kottayam, Kerala. J Evol Med Dent Sci. 2014;3(24):6762-6771.

26. Megha SM, Hetal KR, Sumit J, et al. Nutritional status of under-five children in urban slums of Pune. Int J Med Publ Health. 2014(4): 247-252.

27. Sujendran S, Senarath U, Joseph J. Prevalence of stunting among children aged 6 to 36 months, in the Eastern Province of Sri Lanka. J Nutr Disord Ther. 2015;1(154).

28. Sengupta P, Philip N, Benjamin AI. Epidemiological correlates of under-nutrition in under-5 years children in an urban slum of Ludhiana. Health Popul Perspect Issues. 2010;33(1):1-9.

29. Teshale F, Sahilu A, Lamessa D. Factors associated with stunting among children of age 24 to 59 months in Meskan district,Gurage Zone, South Ethiopia: a case-control study. BMC Public Health. 2014;14:800.

30. Popat CN, Chaudhari AI, Mazumdar VS, Patel SV. A cross sectional study to measure the prevalence of malnutrition and factors associated with malnutrition among under five children of an urban slum of Vadodara city. J Res Med Dent Sci. 2014;2(3):59-64.

31. Mandefro A, Mekitie W, Mohammed T, Lamessa D. Prevalence of undernutrition and associated factors among children aged between six to fifty nine months in Bule Hora district, South Ethiopia. BMC Public Health. 2015;15:41.

32. Bantamen GB, Dube J. Assessment of Factors Associated with malnutrition among under five years age children at Machakel Woreda, Northwest Ethiopia: a case control study. J Nutr Food Sci. 2014;4(1): $1-7$.

33. Monal S, Paula G, Linda A, Chirayath S, Margaret B. Maternal autonomy is inversely related to child stunting in Andhra Pradesh, India. Matern Child Nutr. 2009;5:1.

34. Babatunde RO, Olagunju FI, Fakayode SB, Sola-Ojo FE. Prevalence and determinants of malnutrition among under-five children of farming households in Kwara State, Nigeria. J Agr Sci. 2011;3(3):173-181.

35. Hafsa H, Saima K, Muhammad H. A review of the prevalence and factors responsible for A review of the prevalence and factors responsible for mal-nutrition in Pakistan. Pakistan J Pharm Res. 2015;1(1): 33-37.

36. Magaju PK, Ettyang' GA, Mbagaya GM. Factors associated with the prevalence of under-nutrition in pre-school children in Matisi Peri-Urban Location, Trans-Nzoia District, Kenya. Biol Agr Health Care. 2013; 3:2.

37. Muchina E, Waithaka P. Relation between breastfeeding practices and nutritional status of child aged 0-24 months in Nairobi, Kenya. Afr $J$ Food Agr Nutr Dev. 2010;10:4.

38. Rakesh KN, Padmaja RW, Mallapur MD. Determinants of nutritional status of under - five children - a cross sectional study. Ann Commun Health. 2014;2(2):26-30.

39. Prosper S, Martin-Prével Y, Savy M, et al. An infant and child feeding index is associated with the nutritional status of 6- to 23 month-old children in rural Burkina Faso. J Nutr. 2006;136(3):656-663.
International Journal of General Medicine

\section{Publish your work in this journal}

The International Journal of General Medicine is an international, peer-reviewed open-access journal that focuses on general and internal medicine, pathogenesis, epidemiology, diagnosis, monitoring and treatment protocols. The journal is characterized by the rapid reporting of reviews, original research and clinical studies across all disease areas.

\section{Dovepress}

The manuscript management system is completely online and includes a very quick and fair peer-review system, which is all easy to use. Visit http://www.dovepress.com/testimonials.php to read real quotes from published authors. 